\title{
Análise do uso de repositórios digitais da Universidade Federal do Rio Grande do Norte
}

\author{
Ronnie Anderson Nascimento de Farias \\ Mestre em Ciência da Informação pela Universidade Federal de Pernambuco \\ Bacharel em Biblioteconomia pela Universidade Federal do Rio Grande do Norte \\ E-mail: ronnieufrn@yahoo.com \\ Raimunda Fernanda dos Santos \\ Mestra em Ciência da Informação pela Universidade Federal de Pernambuco \\ Bacharel em Biblioteconomia pela Universidade Federal do Rio Grande do Norte \\ E-mail: nandaflorania@gmail.com
}

\begin{abstract}
RESUMO:
Estuda o uso e a visibilidade dos repositórios institucionais, em especial o da Universidade Federal do Rio Grande do Norte (UFRN). Busca verificar a experiência e a percepção do usuário no que concerne aos repositórios digitais em face ao suprimento das suas necessidades informacionais. Tem como objetivo geral analisar o uso e a visibilidade do Repositório Institucional da UFRN. Visa especificamente analisar se os discentes conhecem os repositórios da instituição de ensino em que fazem parte, bem como identificar quais os repositórios digitais que esses discentes acessam e qual a frequência de uso. Utiliza como metodologia a pesquisa bibliográfica em fontes impressas e eletrônicas; pesquisa descritiva com abordagens quantitativas e qualitativas resultantes da aplicação de 200 questionários no período de janeiro a maio de 2015 e 33 em maio de 2016, cujas questões objetivas e discursivas contemplam os objetivos deste trabalho. Conclui inferindo que a visibilidade dos repositórios institucionais da instituição supracitada ainda é baixa e que não há o conhecimento necessário por parte dos discentes no que concerne ao uso dessas ferramentas. Conclui-se que ainda permanece o baixo índice de uso e preferência da comunidade acadêmica em relação aos repositórios institucionais da universidade como fonte de informação para a busca e recuperação das produções científicas.
\end{abstract}

Palavras-chave: Repositórios institucionais. Publicações de acesso livre. Universidade Federal do Rio Grande do Norte. Comunicação científica.

\section{ABSTRACT:}

Studies the use and visibility of institutional repositories, especially of the Federal Universidade do Rio Grande do Norte (UFRN). Search verify the experience and the perception of the user in relation to digital repositories in relation to the supply of their information needs. It has the general objective to analyze the use and visibility of the Institutional Repository of UFRN. It specifically aims to analyze whether the students know the repositories of educational institution in which they are part, and to identify which digital repositories that these students access and what the frequency of use. Use as methodology the literature in print and electronic sources; descriptive research with quantitative and qualitative approaches resulting from the application of 200 questionnaires from january to may 2015 and 33 in may 2016, whose objective and discursive issues include the objectives of this work. It concludes inferring that the visibility of the institutional repositories of the aforementioned institution is still low 
and that there is the knowledge needed by the students regarding the use of these tools. It follows that still remains low use rate and preference of the academic community to institutional repositories of the university as a source of information for the search and retrieval of scientific production.

Keywords: Institutional repositories. Open access publications. Federal University of Rio Grande do Norte. Scientific communication.

\section{INTRODUÇÃO}

Os repositórios institucionais surgiram como instrumentos tecnológicos que visam congregar uma variada gama de produção científica em um único ambiente padronizado e interoperável. Essas ferramentas vêm proporcionando ampliação da visibilidade da produção intelectual de instituições de Ensino Superior, especialmente no que tange ao acesso livre, preservação da memória institucional e democratização da publicação dos pesquisadores. Para além disso, resguarda a memória digital através do tempo, materializado na produção realizada de artigos científicos, relatórios técnicos, livros, atas, entre outros.

Os repositórios institucionais possibilitam o acesso, a recuperação e o uso da produção acadêmica das universidades. Portanto, surge o seguinte questionamento: qual o índice de visibilidade e de uso dos Repositórios Institucionais Federais pelos discentes das Universidades Federais, em especial na UFRN?

No intuito de responder a indagação apresentada anteriormente, o presente estudo objetiva descrever e analisar a visibilidade e o uso dessas ferramentas que são fontes de informação importantes para a comunidade acadêmica/científica da Universidade Federal do Rio Grande do Norte (UFRN). Dessa forma, a presente pesquisa tem como objetivos específicos: analisar se os discentes conhecem os repositórios da instituição de ensino em que fazem parte, bem como identificar quais os repositórios digitais que esses discentes acessam e qual a frequência de uso.

Desse modo, esta pesquisa foi motivada pela possibilidade de exploração do tema para tentar compreender as particularidades do uso dos repositórios institucionais pelos usuários em uma amostra formada por 200 usuários informantes os quais são discentes da UFRN. É evidente que os Repositórios Institucionais promovem a valorização, reconstrução e divulgação da memória institucional das universidades, e a cada dia que passa essas ferramentas se integram cada vez mais 
no cotidiano dos ambientes acadêmicos, contribuindo assim para a construção do conhecimento e satisfação das necessidades informacionais dos usuários.

\title{
2 OS REPOSITÓRIOS DIGITAIS E A COMUNIDADE DE USUÁRIOS
}

A necessidade de conhecer o perfil dos usuários da informação é imprescindível para planejar, desenvolver e prestar serviços que, de fato, atendam às suas necessidades, conforme ressalta Robredo (2003, p.22):

\begin{abstract}
A transferência do conhecimento ocorre quando o conhecimento é difundido de um indivíduo para o outro ou para o grupo. Muito conhecimento é transferido, por exemplo, por intercâmbio social e cultural. O conhecimento é transferido mediante processo de socialização, educação e aprendizado. $\mathrm{O}$ conhecimento pode ser transferido propositadamente o pode acontecer com o resultado de outra atividade. Esses processos sociais de transferência de conhecimento são resultado de uma forma ou de outra, da decodificação de conhecimento individuais, de grupos ou de organizações, onde a codificação numa linguagem determinada, com níveis variáveis de utilização de terminologias especializadas, dependerá das características do público aqui se destinam.
\end{abstract}

Dessa forma, os profissionais da informação podem visualizar a natureza de seus produtos e serviços e, notadamente, saber que o ponto crítico deixa de ser "quais são os serviços e com que frequência são feitos" e passa a ser "com quais propostas de serviços serão calculados e como serão percebidos e apropriados pelos usuários" (ZWEIZIG \& DERWIN apudFERREIRA, 1996).

Com isso, o conhecimento sobre o usuário é a base da orientação e da concepção do Serviço de Informação, considerando suas características, atitudes, necessidades e demandas. Essas características são complexas e se modificam constantemente. Dessa forma, Dias e Pires (2004, p. 06) relatam que "esses serviços devem ser planejados de acordo com os usuários e a comunidade a ser atingida, com a natureza de suas necessidades de informação e seus padrões de comportamento na busca e no uso da informação, de modo a maximizar a eficiência de tais serviços".

Segundo as autoras citadas anteriormente, são diversificados os fatores que influenciam o comportamento dos usuários em relação à informação, dos quais podem-se citar alguns, como: a formação básica do usuário; treinamento que possui na utilização das fontes, produtos e serviços de informação; acesso a esses serviços; condições de trabalho e tempo que dispõe para busca da informação; grau de instrução; conhecimento de línguas; posição sócio-profissional; sociabilidade; 
grau de competição dentro do grupo de atuação e a imagem que cada um tem da informação e das experiências anteriores.

Assim, a biblioteca universitária se apoia na função social em meio digital, levando em consideração que no atual contexto social os usuários estão satisfazendo as suas demandas informacionais por meio da Internet. Diante disso, a criação de acervos digitais passou a ser um dos caminhos que contribuirá para projetos colaborativos de pesquisa científica.

A ideia de um acervo digital já era posta em discussão, haja vista que o armazenamento e a organização de documentos nesse contexto ampliam as possibilidades de visualização e acesso dos documentos, principalmente quando termos/descritores de indexação precisos e coerentes são associados ao mesmo como pontos de acesso em sua representação contribuindo assim para a sua recuperação em meio digital.

Destarte, os Repositórios Institucionais dispõem de mecanismos que possibilitam o aumento da visibilidade e da eficácia da preservação das produções científicas dos pesquisadores e das instituições acadêmicas. Dessa forma, tais ferramentas devem "servir como indicadores tangíveis da qualidade de uma universidade e demonstrar a relevância científica, social e econômica de suas atividades de pesquisa, aumentando a visibilidade, o status e o valor público da instituição" (CROW, 2002, p. 01).

Em consonância de evidências, Dodebei (2009, p.91) enfatiza que:

\footnotetext{
Um repositório institucional é uma base de dados digital e virtual (web-based database), de caráter coletivo e cumulativo (memória da instituição), de acesso aberto e interoperável que coleta, armazena, dissemina e preserva digitalmente a produção intelectual da instituição.
}

No Brasil, de acordo com os dados recuperados em janeiro de 2016 existem 12 Repositórios descritos pelo OpenDOAR e o Brasil ocupa a 8 posição no ranking dos Rls. O Gráfico 1 a seguir apresenta os tipos de Repositórios no país e as respectivas porcentagens.

Gráfico 1 - Porcentagem de tipos de repositórios no Brasil em 2016. 


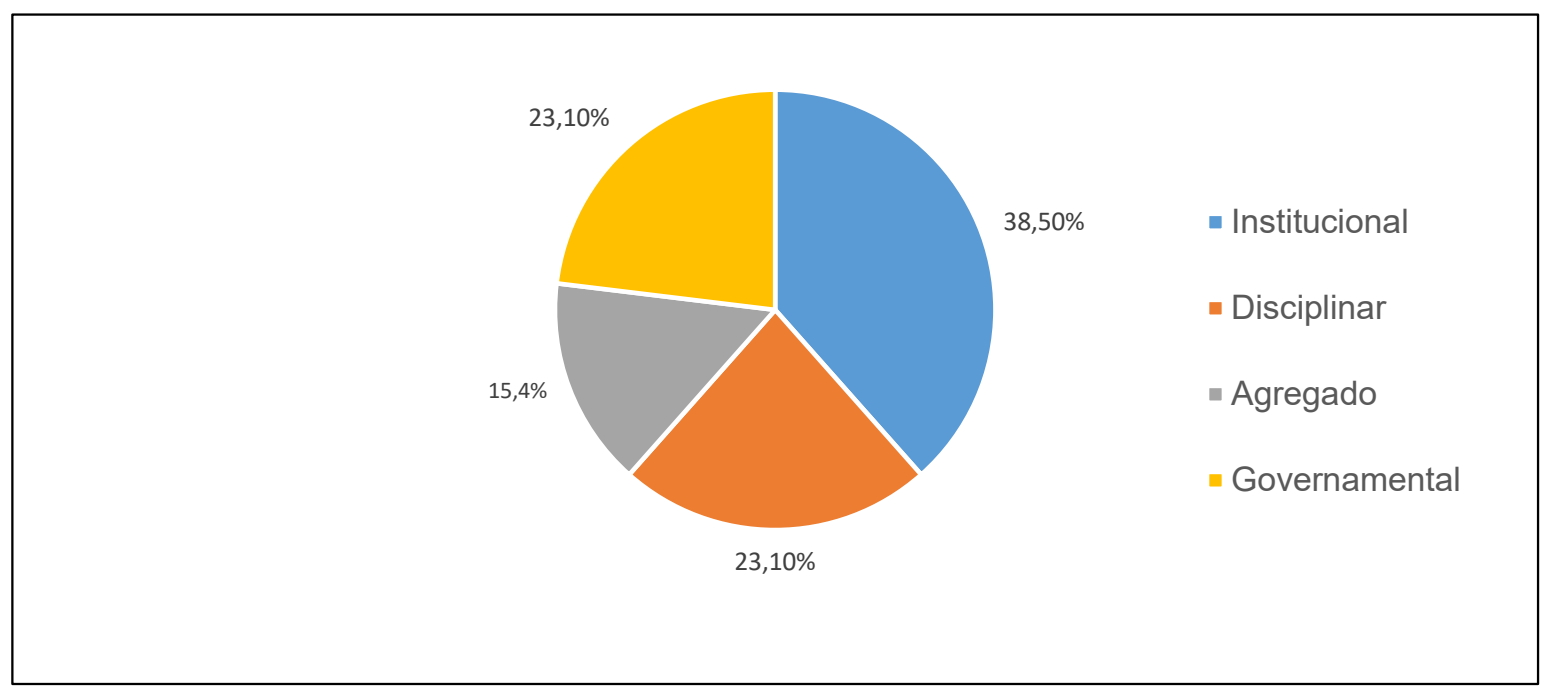

Fonte: OpenDOAR (2016).

Conforme verificado, a maioria dos Repositórios Digitais existentes no Brasil possuem caráter institucional. Para Well (2009, p.59, tradução nossa), há uma falta de conhecimento quanto ao tipo de grupos de usuários que estão associados aos repositórios". O resultado dessa investigação, que ilustra um número de grupos de usuários, incluem também os usuários que acessam os repositórios públicos de informação por razões que não são acadêmicas. Há também uma série de grupos de profissionais associados aos repositórios, incluindo aqueles que utilizam sites governamentais e comerciais. "Estes grupos de usuários são importantes no alargamento do acesso à produção de pesquisa acadêmica, tanto formal como informalmente, o que é importante para repositórios institucionais e ensino superior em geral" (WELL, 2009, p.59, tradução nossa).

Então, para beneficiar a pesquisa sobre os usuários dos Repositórios Digitais Institucionais, estudos específicos tentam entender seu perfil, bem como o(s) seu(s) objetivo(s) ao consultar o Repositório Institucional. Sob esse entendimento, Jack Maness, Tomaz Miaskiewicz e Tamara Sumner (2008) descobriram que o real objetivo e as necessidades dos potenciais utilizadores dos repositórios foram bastante diferentes do que aqueles planejados para um novo Repositório Institucional da Universidade do Colorado (EUA). Enquanto esses autores acreditavam que os usuários do Repositório Institucional gostariam principalmente de ter acesso à coleção de materiais de pesquisa publicadas de docentes e pósgraduandos, a pesquisa de tais autores indicou que os potenciais usuários gostariam 
de compartilhar os materiais de ensino e aprendizagem por meio de uma rede, encontrar potenciais colaboradores e promover as suas pesquisas para os colegas.

Com isso, Jean et al. (2011) em seu estudo diz que:

Nós não sabemos de onde os usuários finais do Repositório Institucional (RI) estão vindo, como eles encontraram o RI, o que eles procuram no RI e como eles usam a funcionalidade disponível do RI. Nós também não sabemos quem são os usuários finais, como eles estão usando conteúdo do $\mathrm{RI}$, e como eles estão satisfeitos com a qualidade do conteúdo do RI (JEAN et al., 2011, p. 24, tradução nossa).

Rumsey (2010) registrou que um grande esforço vem sendo feito para investigar as necessidades dos usuários e obter feedback sobre como o desenvolvimento dos Rl's deve ser priorizado, a fim de atender as necessidades dos usuários. Russell e Day (2010) mostraram que apesar do crescimento e das melhorias dessas ferramentas, as baixas taxas de depósito continuaram em muitos Repositórios Institucionais significando que ainda faltavam estratégias que poderiam ser feitas para atrair os usuários. Mediante tais considerações, observa-se que algumas instituições ainda precisavam se envolver mais com os seus usuários de pesquisa e adaptar às necessidades de sua própria equipe, usando uma linguagem que seja significativa em diferentes contextos culturais e que demonstrem que os planos e políticas do seu Repositório fossem adaptados às necessidades e às percepções específicas dos seus consulentes.

Por isso, entender o que procura o usuário e fornecer ferramentas que possam atendê-lo no que concerne às suas necessidades informacionais é de fundamental importância para as instituições que disponibilizam repositórios institucionais como fonte de informação para a recuperação, acesso e uso das produções científicas dos seus pesquisadores.

Levando em consideração os aspectos enfatizados anteriormente, a presente pesquisa objetiva descrever e analisar a visibilidade e o uso dessas ferramentas que são fontes de informação importantes para a comunidade acadêmica/científica. Em particular são analisados a visibilidade e o uso do Repositório Institucional da Universidade Federal do Rio Grande do Norte (UFRN). 


\subsection{REPOSITÓRIO INSTITUCIONAL DA UFRN: MISSÃO, POLÍTICA E TIPOS DE PRODUÇÕES CIENTÍFICAS}

O Repositório Institucional da Universidade Federal do Rio Grande do Norte reúne a produção intelectual da comunidade universitária (docentes, técnicos e alunos de pós-graduação) da instituição. Sua missão é armazenar, preservar e disponibilizar na Internet, textos completos de acesso livre. Para tanto, foi criada a Resolução $\mathrm{n}^{\circ}$ 059/2010-CONSEPE, de 13 de abril de 2010, que estabelece normas sobre a Política Institucional de Informação Técnico-Científica na UFRN, no que se refere ao seu Repositório Institucional. A plataforma utilizada é o Dspace ${ }^{1}$ e os objetivos são:

- Gerir e disseminar a produção técnico-científica em meio digital;

- Proporcionar maior visibilidade dessa produção institucional;

- Preservar a memória intelectual da universidade;

- Servir como indicador tangível de qualidade e de relevância científica, econômica e social.

De acordo com a Biblioteca Digital de Teses e Dissertações - BDTD (2015) os documentos autorizados para publicação no Repositório Institucional foram aprovados mediante a Resolução $n^{\circ}$ 059/2010-CONSEPE e são os seguintes:

- Artigos publicados em periódicos

- Trabalhos completos apresentados em eventos;

- Dissertações e Teses Defendidas na instituição;

- Capítulos de Livros;

Segundo o OpenDoar², os registros do RI da UFRN são conforme o quadro abaixo:

\footnotetext{
${ }^{1}$ Software de código aberto para a criação e implementação de Repositórios Digitais visando gerenciar e preservar os registros informacionais disponíveis nesse contexto.

2 Diretório de Repositórios de Acesso Aberto.
} 
Quadro 2 - Repositório Institucional da Universidade Federal do Rio Grande do Norte (2016)

\begin{tabular}{|c|c|}
\hline Organização: & Universidade Federal do Rio Grande do Norte (UFRN), Brasil \\
\hline Descrição: & $\begin{array}{l}\text { Este site fornece acesso à saída da instituição de pesquisa. Os } \\
\text { usuários podem configurar feeds RSS para ser alertado para novos } \\
\text { conteúdos. A interface está disponível em Inglês. }\end{array}$ \\
\hline OAI-PMH: & http://repositorio.ufrn.br:8080/oai/request \\
\hline Software: & DSpace \\
\hline Tamanho: & 7316 itens $(27 / 10 / 2015)$ \\
\hline Assuntos: & Multidisciplinar \\
\hline Conteúdo: & Artigos; Teses; Especial \\
\hline Idiomas: & Português; Inglês \\
\hline Políticas: & $\begin{array}{l}\text { Metadados política de reutilização explicitamente indefinido; Políticas } \\
\text { de itens de dados completos explicitamente indefinidos; Políticas de } \\
\text { conteúdo explicitamente indefinido; Políticas de submissão } \\
\text { explicitamente indefinido; Políticas de preservação explicitamente } \\
\text { indefinido }\end{array}$ \\
\hline AbrirDOAR ID: & $\begin{array}{l}\text { 2111, Última avaliação: 23/03/2011, Sugerir uma atualização para este } \\
\text { registro, falta de dados é necessária para: Políticas } \\
\text { Link para este registro: http://opendoar.org/id/2111/ }\end{array}$ \\
\hline
\end{tabular}

De outro modo disposto, objetivando analisar se os discentes conhecem os Repositórios Institucionais da UFRN, bem como identificar quais os repositórios digitais que esses alunos acessam (e qual a frequência de uso) - foi aplicado um questionário sobre o Repositório Institucional dessa Universidade com os alunos da instituição no intuito de cumprir com os objetivos da presente pesquisa, bem como saber o perfil dos informantes e investigar também se os mesmos utilizam e qual o grau de sua satisfação no que concerne à busca e recuperação da informação nos Repositórios Institucionais. Para tanto, a seguir, será descrita a metodologia do presente estudo.

\subsection{METODOLOGIA}

Os procedimentos metodológicos para a realização do presente trabalho foram realizados a partir de uma pesquisa bibliográfica para a fundamentação teórica 
desta pesquisa, seguido de uma pesquisa descritiva com abordagem qualitativa e quantitativa.

Sendo assim, para a realização da pesquisa bibliográfica foram consultados trabalhos referentes ao tema aqui exposto em fontes impressas como livros e em meio digital (periódicos eletrônicos, bases de dados, repositórios digitais, etc.).

De outro modo disposto, o presente trabalho se configura como uma pesquisa descritiva haja vista que, mediante a aplicação de questionário, tornou-se possível descrever e analisar a visibilidade e o uso do Repositório Institucional da UFRN, bem como analisar se os discentes conhecem os repositórios dessa instituição e identificar quais os repositórios digitais que eles acessam, verificando também a sua frequência de uso.

Conforme mencionado anteriormente, a coleta de dados foi realizada por meio de questionários que apresentaram perguntas distintas (objetivas e discursivas) relevantes para as análises quantitativas e qualitativas desta pesquisa. "A coleta de dados significa a fase da pesquisa em que se indaga e se obtêm dados da realidade pela aplicação das técnicas" (BARROS; LEHFELD, 2000, p.89).

Após a coleta das respostas dos informantes nos questionários, tais dados foram representados por tabelas e gráficos, os quais serão elencados posteriormente.

Para iniciar a pesquisa sobre o uso dos repositórios, foi realizado um préteste na Universidade Federal de Pernambuco no ano de 2014, e depois do resultado, verificou-se a necessidade de confirmar ou refutar os dados levantados, reformulações das questões, como forma de eliminar possíveis erros e duplicidade de respostas nos dados coletados. Após isso, realizou-se a aplicação de dos questionários na Universidade Federal do Rio Grande do Norte (UFRN) baseado no pré-teste. A amostra analisada foi de 200 usuários informantes que participaram desta pesquisa a qual gerou os dados das respostas no período de janeiro a maio do ano de 2015.

O questionário foi feito de perguntas fechadas e abertas que apresentam categorias ou alternativas de respostas fixas adequadas para a obtenção de informação sobre fatos e expressões de opinião a respeito das quais as pessoas já têm ideias formadas e claras. Para a elaboração do questionário foram vistos e analisados os fatores que influenciam o comportamento dos usuários em relação à informação, relatados por Dias e Pires (2004), como: a formação básica do usuário; 
acesso a esses serviços, como por exemplo a BDTD e ao RI e grau de instrução, visto nas questões 7 e 8 . Retomando também outros fatores foram analisados como dois fatores que têm influência de maneira decisiva na busca pela informação. São eles, segundo Leckie, Pettigrew e Sylvain (1996):

- Fontes de informação: locais onde são procuradas as informações.

- Conhecimento da informação: os conhecimentos direto ou indireto das fontes de informação, do próprio processo de busca e da informação disponível e recuperada nessas fontes constituem-se como fatores que desempenham importante papel no sucesso da busca. Que foram utilizadas nas questões 4, 5 e 6 do instrumento de avaliação.

Brenda Dervin (1998) relatou que o questionamento aos usuários no que concerne ao uso ou não uso do sistema, bem como se eles encontram o que procuram é interessante para a obtenção de respostas relativas à busca informacional. Para tanto, tal concepção foi levada em consideração para a elaboração do questionário - cujos questionamentos estão correlacionados com as perguntas 5 e 6, haja vista que o usuário define qual a informação é útil de acordo com suas próprias conclusões.

O Repositório Institucional difere de outras bases de dados, levando em consideração que essa ferramenta viabiliza a interação e a troca com seus usuários (MARCONDES; SAYÃO, 2009). Nesse contexto, verifica-se a necessidade de saber se esse usuário conhece essa ferramenta oferecida pela instituição de ensino na qual ele faz parte, e ao mesmo tempo saber se essa informação é útil para pesquisa dos usuários informantes. Portanto, esse questionamento foi incluído também no questionário.

Em linhas gerais, o primeiro passo do experimento foi a coleta dos dados através da aplicação do questionário tanto em meio físico (impresso) quanto digital. O questionário digital foi elaborado por meio da ferramenta do Google Doc e aplicado por meio das comunidades do Facebook da UFRN, a escolha das comunidades foi por alcançar os alunos de forma mais aleatória e com maior número de respostas. O segundo passo consistiu da normalização e mapeamento dos dados. No terceiro passo, a utilização de uma política rigorosa de qualidade dos dados levou a realização de uma série de cruzamentos de respostas entre perguntas para transferir os dados para gráficos e tabelas. Além disso, a corretude das respostas de perguntas abertas também foi cuidadosamente verificada. Os 
respondentes que tiveram respostas inconsistentes e inválidas foram inteiramente eliminados.

No total, foram analisados 200 questionários na Universidade Federal do Rio Grande do Norte no ano 2015 e 33 em 2016 (sendo que esses últimos foram aplicados somente em meio digital a duas turmas do curso biblioteconomia, para o início da aplicação dos questionários).

O questionário físico e digital foi conforme o quadro abaixo, anônimo e com o termo de consentimento esclarecido aos participantes. 
Quadro 3 - Questionário sobre Repositórios Institucional da UFRN

1. Informe aqui a sua formação acadêmica e o curso:

( ) Graduação

( ) Especialização

( ) Mestrado

( ) Doutorado

2. De que forma você busca conhecimento acadêmico?

( ) Bibliotecas

) Repositórios Digitais

( ) Buscadores online (Google, Bing Yahoo, etc.)

( ) Outros

É permitido marcar mais de uma alternativa.

\section{Você usa repositórios digitais?}

( ) Semanalmente

( ) Mensalmente

( ) Não acho útil / não encontro o que quero

( ) Não sei o que é um repositório digital

4. Quais são os repositórios digitais que você já acessou?

( ) Repositório Institucional da UFRN

( ) Outro

É permitido marcar mais de uma alternativa.

5. Você conhece a Biblioteca Digital de Teses e Dissertações (BDTD)?

( ) Conheço e a utilizo

( ) Tenho conhecimento, mas não a uso

( ) Não a conheço

Pode ser acessado no site http://bdtd.ufrn.br/

\section{Você conhece o Repositório Institucional da UFRN?}
( ) Conheço e utilizo
) Tenho conhecimento, mas não o uso
) Não o conheço

O Repositório Institucional reúne a produção intelectual da comunidade universitária (docentes, técnicos e alunos de pós -graduação) da Universidade Federal do Rio Grande do Norte (UFRN) (http://repositorio.ufrn.br:8080/jspui/).

O objetivo geral da pesquisa é analisar o uso dos Repositórios Institucionais e realizar estudo sobre a necessidade informacional dos usuários das comunidades acadêmicas. Somos um grupo de pesquisa da UFPE que teve a aprovação do CEP/ UFPE (Comitê de Ética em Pesquisa) com o parecer aprovado $\mathrm{n}^{\circ} 897.694$, a qual declara o termo de consentimento: ( ) Fui devidamente esclarecido quanto aos objetivos e procedimentos envolvidos na pesquisa, concordo livremente em ceder dados para fins da pesquisa descrita acima.

Fonte: autoria própria. 


\section{RESULTADOS}

Foram analisados 200 questionários na Universidade Federal do Rio Grande do Norte no ano de 2015. 35,5\% dos informantes enfatizaram que sabem o que é e usam o Repositório Institucional da UFRN (RI/UFRN), porém não encontram o que procuram. De outo modo disposto, $64,5 \%$ dos discentes informaram que não sabem o que é o Repositório Institucional da UFRN, representando assim os usuários que não usam o RI/UFRN.

Tabela 1 - Dados sobre o conhecimento do RI dos usuários da UFRN

\begin{tabular}{lc}
\hline Sabem o que é RI & $35,5 \%$ \\
\hline Não sabem o que é RI & $64,5 \%$ \\
\hline Sem Resposta & $0 \%$ \\
\hline Total & $100 \%$
\end{tabular}

Fonte: autoria própria.

Dos informantes que não usam o RI (64,5\%), 95\% deles representam os alunos de graduação da UFRN. Já aqueles discentes que não conhecem essa ferramenta representam $70,86 \%$ dos alunos de graduação da UFRN, conforme a Tabela 2 abaixo, cujos dados também apresentam os informantes que são discentes de pós-graduação.

Tabela 2 - Você usa Repositório Institucional?

\begin{tabular}{lccccc}
\hline & $\begin{array}{c}\text { Aluno de } \\
\text { graduação }\end{array}$ & $\begin{array}{c}\text { Aluno de pós- } \\
\text { graduação } \\
\text { especialização }\end{array}$ & $\begin{array}{c}\text { Aluno de } \\
\text { mestrado }\end{array}$ & Mestre & Total \\
\hline $\begin{array}{l}\text { Não acho útil / } \\
\text { não encontro o } \\
\text { que quero }\end{array}$ & $25,1 \%$ & $0,78 \%$ & $0 \%$ & $0 \%$ & $26 \%$ \\
\hline $\begin{array}{l}\text { Não sei o que é } \\
\text { um repositório } \\
\text { digital }\end{array}$ & $70,86 \%$ & $0,78 \%$ & $1,5 \%$ & $0 \%$ & $74 \%$ \\
\hline Total & $95.9 \%$ & $1,5 \%$ & $1,5 \%$ & $0,78 \%$ & $100 \%$ \\
\hline
\end{tabular}

Fonte: autoria própria. 
$\mathrm{Na}$ forma de busca do conhecimento acadêmico, 60 ou $30 \%$ dos alunos incluíram o RI como fonte de pesquisa, e 139 ou $69,5 \%$ dos alunos não o incluíram como fonte de pesquisa. As bibliotecas e buscadores online continuam sendo a fonte de informação de maior procura dos usuários. Dos que usam o repositório como fonte de informação, apenas 36 conhecem o RI da UFRN. Os que não conhecem o RI da UFRN são 85 alunos. Há alunos que conhecem e não utilizam por não acharem útil, que somam cerca de 146.

Os usuários que não usam o RI foram 127 alunos, com $63,5 \%$, e os motivos foram que não encontram o que buscam e não sabem o que é um RI.

Tabela 3 - Dados sobre o não uso do RI da UFRN

\begin{tabular}{lrr}
\hline Não acho útil / não encontro o que quero & 33 & $16,5 \%$ \\
\hline Não sei o que é um repositório digital & 94 & $47 \%$ \\
\hline Total Geral & 127 & $63,5 \%$
\end{tabular}

Fonte: autoria própria

A tabela 4 mostra como os acadêmicos da UFRN, que responderam ao questionário, buscam o conhecimento acadêmico.

\section{Tabela 4 - Como buscam o conhecimento acadêmico na UFRN}

\begin{tabular}{lc}
\hline RI como fontes de Informação & Porcentagem \\
\hline Usam repositórios digitais & $30,5 \%$ \\
\hline Não usam repositórios digitais & $69,5 \%$ \\
\hline Total Geral & $100 \%$
\end{tabular}

Fonte: autoria própria.

Os que usam o RI da UFRN são 78 usuários dos 200 questionários respondidos, representando 39\%. De outro modo disposto, 37 alunos (representando $23,8 \%$ ) informaram que nunca acessaram um RI. Os usuários que não responderam o que eles usam para a busca científica foram 14, e outros Repositórios Digitais ou fontes de informação que eles acessam e que foram mencionados nos questionários são os seguintes: BDTD, CAPES, Scielo, UFRGS, SENAC, UNICAMP, Scienc 
Direct, UFBA e USP. Por fim, 45 usuários não responderam a esse quesito, representando $22,5 \%$.

Tabela 5 - Dados sobre o acesso ao Repositório Institucional da UFRN

\begin{tabular}{lc}
\hline Acessam ao RI da UFRN & Quantidade \\
\hline RI UFRN & $50,3 \%$ \\
\hline Outros RI & $16,7 \%$ \\
\hline Diversos & $9,03 \%$ \\
\hline Nunca acessou ao RI & $23,8 \%$ \\
\hline TOTAL & $100 \%$
\end{tabular}

Fonte: autoria própria.

Os usuários que conhecem e utilizam o RI foram 18\%, dos 189 informantes que responderam a essa questão. Já os que não usam o RI, por não conhecerem ou não acharem útil diz respeito a 74,5\% dos informantes. Conforme as tabelas 6 e 7.

Tabela 6 - Dados quantitativos sobre os que conhecem e usam o RI da UFRN

\begin{tabular}{lcccccc}
\hline $\begin{array}{l}\text { Você } \\
\text { conhece o } \\
\text { RI da } \\
\text { UFRN? }\end{array}$ & $\begin{array}{c}\text { Aluno de } \\
\text { graduação }\end{array}$ & $\begin{array}{c}\text { Aluno de pós- } \\
\text { graduação } \\
\text { especialização }\end{array}$ & Doutorado & Mestre & Professor & Total \\
\hline $\begin{array}{l}\text { Conheço } \\
\text { e utilizo }\end{array}$ & $15,8 \%$ & $1,58 \%$ & $0,5 \%$ & $0,5 \%$ & $0,5, \%$ & $18,8 \%$ \\
\hline
\end{tabular}

Fonte: autoria própria.

Na tabela a seguir tem a porcentagem dos usuários que não conhecem o RI da UFRN, totalizando assim 42,9\%. Pode-se analisar também o quantitativo de alunos que tem conhecimento do RI, 32,2\%, mas prefere não usar. Esse somatório ultrapassa a $70 \%$ dos usuários que não faz uso do RI UFRN.

Tabela 7 - Dados quantitativos dos usuários que não conhecem e não usam o RI da UFRN

\begin{tabular}{lcclc}
\hline Você conhece o & Aluno de pós- & & \\
RD UFRN? & gluno de & graduação & Aluno de & \\
& & especialização & mestrado & Total
\end{tabular}




\begin{tabular}{lccccc}
\hline & & & & \multicolumn{2}{l}{ Mestre } \\
\hline $\begin{array}{l}\text { Tenho } \\
\text { conhecimento }\end{array}$ & $30,68 \%$ & $1,05 \%$ & $0,5 \%$ & $0 \%$ & $32,2 \%$ \\
mas não o uso & & & & & \\
\hline Não o conheço & $39,8 \%$ & $0 \%$ & $2,64 \%$ & $0,5 \%$ & $42,9 \%$ \\
\hline Total & $70,4 \%$ & $1,05 \%$ & $3,14 \%$ & $0 \%$ & $74,5 \%$ \\
\hline
\end{tabular}

Fonte: autoria própria.

\subsection{RESULTADO DOS DADOS COLETADOS EM 2016}

Foi iniciada uma nova coleta de dados neste ano de 2016, mediante a aplicação de um questionário em meio digital. Foram coletados dados referentes ao questionário digital aplicado com obtenção de respostas de 33 alunos de graduação, cujos resultados são apresentados nas tabelas a seguir. A tabela 8, por exemplo, mostra que os repositórios digitais ainda não são uma escolha preferencial dos alunos, visto que usam os buscadores online e as bibliotecas para pesquisa universitária, mesmo fato evidenciado no questionário aplicado no ano de 2015.

Tabela 8 - De que forma você busca o conhecimento acadêmico?

\begin{tabular}{lrr}
\hline Bibliotecas & 21 & $65.6 \%$ \\
\hline Repositórios Digitais & 16 & $50 \%$ \\
\hline Buscadores online (Google, etc) & 22 & $68.8 \%$ \\
\hline Outros & 8 & $25 \%$
\end{tabular}

Fonte: autoria própria.

O número dos informantes que ainda não utilizam o Repositório Institucional, por não achar útil e não saber o que é um RI, chega ao somatório de $21,2 \%$ - o qual supera os alunos que usam com frequência, semanalmente e mensalmente $18,2 \%$. Os alunos ainda não fazem uso do RI como fonte de informação, pois a prevalência é de "ás vezes". 
Tabela 9 - V usa repositórios institucionais?

\begin{tabular}{lrr}
\hline Semanalmente & 3 & $9.1 \%$ \\
\hline Mensalmente & 3 & $9.1 \%$ \\
\hline Às vezes & 20 & $60.6 \%$ \\
\hline Não acho útil / não encontro o que quero & 3 & $9.1 \%$ \\
\hline Não sei o que é um repositório digital & 4 & $12.1 \%$
\end{tabular}

Fonte: autoria própria.

O conhecimento da existência do RI da UFRN demonstra que o marketing utilizado para a divulgação dessa ferramenta está sendo efetivo, apesar de ser identificado que poucos discentes usam o Repositório da Instituição - cujo dado está elencado na Tabela 9. De outro modo disposto, 12,1\% dos discentes não sabem o que é um Repositório Digital.

\begin{tabular}{lcc} 
Tabela 10 - Quais são os repositórios digitais (RD) que você já acessou? \\
\hline Repositório Institucional da sua Universidade - UFRN & 25 & $75.8 \%$ \\
\hline Nunca acessei nenhum repositório & 4 & $12.1 \%$ \\
\hline Outros & 4 & $12.1 \%$
\end{tabular}

Fonte: autoria própria.

Na tabela 11 verifica-se que o número dos informantes que não usam ainda o Repositório Institucional persiste por pouca diferença, conforme pode ser visualizado a seguir.

Tabela 11 - Você conhece o RI da sua universidade?

\begin{tabular}{lrr}
\hline Conheço e utilizo & 16 & $48.5 \%$ \\
\hline Tenho conhecimento, mas não o uso & 13 & $39.4 \%$ \\
\hline Não o conheço & 4 & $12.1 \%$ \\
\hline Outros & 0 & $0 \%$
\end{tabular}

Fonte: autoria própria. 


\section{CONSIDERAÇÕES PARCIAIS}

Diante do exposto, os dados e as reflexões apresentadas anteriormente conduzem à reflexão de que o Repositório Institucional da UFRN reúne a produção intelectual da comunidade universitária (docentes, técnicos e alunos de pósgraduação) da Universidade Federal do Rio Grande do Norte (UFRN). Sua missão é armazenar, preservar e disponibilizar na Internet, textos completos de acesso livre.

$\mathrm{Na}$ UFRN 35\% dos que responderam o questionário relatam conhecer o que significa o RI da UFRN. Eles buscaram o conhecimento através do RI, com cerca de $35 \%$ de usuários, e os que utilizaram o RI da UFRN foram $50 \%$.

Os usuários que não sabem o que é o RI representam $64 \%$. De outro modo disposto, cerca de $69 \%$ os discentes não incluíram o RI como fonte de informação, haja vista que as bibliotecas e buscadores online continuam sendo a fonte de informação de maior procura para esses usuários. Os usuários responderam que utilizaram outras fontes como: BDTD, CAPES, IBICT, Scielo, UFRGS, SENAC, UNICAMP, Scienc Direct, UFBA e USP. Já os que não usam o RI, por não conhecerem ou não acharem útil, são cerca de 146 alunos, representando assim $74,5 \%$, do ano de 2015 e $51 \%$ dos informantes do instrumento de avaliação aplicado em 2016.

A análise dos dados mostra que os discentes questionados da UFRN ainda não conhecem em sua totalidade a existência do RI da instituição. Com isso, para buscar o conhecimento acadêmico preferem fazer uso de bibliotecas e buscadores on-line, ficando o RI na terceira opção. Pode-se inferir também que o Repositório Institucional da UFRN foi reconhecido por um número reduzido de usuários. Além disso, certa parcela desses discentes que afirmaram que conhecem a ferramenta, dizem que não a utiliza haja vista que não encontram o que procuram para satisfazer as suas necessidades informacionais.

Dessa forma vê-se que os usuários que responderam o questionário buscam fonte de informação com uso de motores de busca como o Google e também as bibliotecas físicas. O número de usuários que usaram o $\mathrm{Rl}$ frequentemente é muito inferior à grande maioria que não sabe o que é essa ferramenta. Do mesmo modo a BDTD, segue a mesma resposta alcançada nos questionários, pois os alunos em sua grande maioria não a conhecem e os que a conhecem não fizeram uso da mesma. 
Em 2016 será dada a continuidade das pesquisas para comparação de dados e os motivos pelos quais houve mudanças nos resultados obtidos, bem como ver se há alguma ação efetiva para mudar o quadro, levando em consideração que os resultados obtidos até agora ainda mostram um cenário semelhante ao de 2015.

O perfil dos usuários continua sendo em sua maioria alunos da graduação. Tais discentes revelaram que ainda não conhecem os Repositórios Institucionais e não fizeram uso dessas ferramentas para a realização de suas pesquisas acadêmicas, optando assim pelo acesso aos buscadores online.

Portanto, é possível inferir que diante dos dados e reflexões apresentadas anteriormente é possível contribuir com uma parcela significativa para a proposição de ações que possam beneficiar a comunidade acadêmica no que concerne à visibilidade e ao uso dos Repositórios Institucionais - levando em consideração que os repositórios institucionais das Universidades Federais do Brasil representam um avanço tecnológico na comunicação científica. Tais ferramentas permitem o acesso a todos e podem ser a porta aberta para a conexão ao conhecimento e ao desenvolvimento cultural da sociedade. Portanto, é evidente uma política de gestão do conhecimento para preservar e disseminar os dados obtidos nos repositórios acadêmicos, reconhecendo ser vital para as instituições e para seus usuários.

\section{REFERÊNCIAS}

BARROS, A. J. S.; LEHFELD, N. A. S. Fundamentos de Metodologia: um guia para a iniciação científica. 2. ed. São Paulo: Makron Books, 2000.

CUNHA, Murilo Bastos da. Construindo o futuro: a biblioteca universitária brasileira em 2010. Ciência da Informação, Brasília, v. 29, n. 1, p. 71-89, 2000.

CROW, R. The case for institutional repositories: a SPARC position paper. The Scholarly Publishing \& Academic Resources Coalition 21 Dupont Circle. DC:

Washington, 2002. Disponível em:<http://www.arl.org/sparc/bm doc/ir_fial_release_ 102.pdf>. Acesso em: 15 dez. 2015.

DERVIN, Brenda. Sense-making theory and practice: an overview of user interests in knowledge seeking and use. Journal of Knowledge Management, v. 2, n.2, p. 36 - 46, 1988. 
DIAS, Maria Matilde Kronka; PIRES, Daniela. Usos e usuários da informação. São Carlos: EdUFSCar, 2004. 48p.

DODEBEI, Vera. Repositórios institucionais: por uma memória criativa no ciberespaço. In: SAYÃO, Luis Fernando et al. (Org.). Implantação e gestão de repositórios institucionais: políticas, memória, livre acesso e preservação. Salvador: EDUFBA, 2009. 365 p.

FERREIRA, S. M. P. Novos paradigmas da informação e novas percepções do usuário. Ciência da Informação, Brasília, v. 25, n. 2, p. 217-223, maio/ago. 1996. Disponível em: <http://revista.ibict.br/index.php/ciinf/article/view/440/398>. Acesso em: 3 mar. 2015.

LECKIE, G. J.; PETTIGREW, K. E.; SYLVAIN, C. Modeling the information seeking of professional: a general model derived from research on engineers, health care professionals and lawyers. Library Quarterly, v. 66, n. 2, p. 161-193, 1996.

MANESS, Jack M.; MIASKIEWICZ, Tomasz; SUMNER, Tamara. Using Personas to Understand the Needs and Goals of Institutional Repository Users. D-lib Magazine, Colorado, v. 10, n. 9, jul. 2008. Disponível em: <www.dlib.org/dlib/ september08/maness/09maness.html>. Acesso em: 18 jun. 2015.

MARCONDES, Carlos Henrique; SAYÃO, Luis Fernando. Software livres para repositórios institucionais: alguns subsídios para a seleção. In: SAYÃO, Luis Fernando et al.(Org.). Implantação e gestão de repositórios institucionais: políticas, memória, livre acesso e preservação. Salvador: EDUFBA, 2009b. 365 p.

OPENDOAR. The Directory of Open Access Repositories. University of Nottingham (UK), 2016. Disponível em:< http://www.opendoar.org/>. Acesso em: 25 jan. 2016.

ROBREDO, J. Da ciencia da informação revisitada aos sistemas humanos de informação. Brasília: Thesaurus, SSRR Informações, 2003.

RUMSEY, Sally. Case Study: Oxford University Research Archive (ORA). Open Repositories 2008, Oxiford, p.1-10, mar. 2008. Disponível em: < http://ora.ox.ac.uk lobjects/uuid:77f86391-4480-4c74-8143-eea1147141f8>. Acesso em: 20 jun. 2015.

RUSSELL, Rosemary; DAY, Michael. Institutional Repository Interaction with Research Users: A Review of Current Practice. New Review of Academic Librarianship, v. 16, n. S1, 2010, p.116-131. Disponível em: http://www.Informa world.com/smpp/ftinterface $\sim \mathrm{db}=$ all $\sim$ content=a928307770 $\sim$ fulltext $=713240930$. Acesso em: 18 jun. 2015.

UNIVERISDADE FEDERAL DO RIO GRANDE DO NORTE. Repositório Institucional. Disponível em:< http://repositorio.ufrn.br:8080/jspui>. Acesso em: 2 maio 2015.

WELL, Paul. Institutional Repositories: Investigating User Groups and Comparative Evaluation Using Link Analysis. 2009. Tese de mestrado University of the West of England. Disponível em: http://eprints.rclis.org/16519/. Acesso em: 16 abr. 2015. 